\title{
LETTERS TO THE EDITOR
}

\section{George Huntington: the man behind the eponym}

In their portrait of George Huntington, Durbach and Hayden' stated that all biographical sources available were investigated. However, they did not mention a relevant paper on George Huntington (1850-1916) and George Sumner Huntington (1861-1927). ${ }^{2}$ The latter was a well known American anatomist of the late 19th century and the first decades of the 20th century. Since 1908, biographical data of these two doctors have been confused repeatedly. ${ }^{2}$ Furthermore, it appeared that biographical publications concerning both George Huntington and George Sumner Huntington contained numerous inaccuracies. ${ }^{2}$ We have corrected the record, provided additional information, and investigated the lineage of both doctors since 1633 to elucidate their relationship.

\section{R M F VAN DER WEIDEN De Lichtenberg Utrechtseweg 160 818 ES Amersfoort}

1 Durbach N, Hayden MR. George Huntington: the man behind the eponym. I Med Genet the man behind

2 van der Weiden RMF. George Huntington and George Sumner Huntington. A tale of two doctors. Hist Phil Life Sci 1989;11:297-304.

\section{DNA storage and duplicate sampling: lessons learnt from testing for Huntington's disease}

Testing for late onset diseases such as Huntington's disease (HD) may lead to a small number of discrepancies in results, mostly because of non-paternity and faulty DNA sampling, storage, or extraction. ${ }^{1}$ Our experience in the Northern Ireland (NI) HD predictive testing programme illustrates how double sampling of DNA may help reduce errors.

Since starting predictive testing in 1990 over 150 at risk HD patients have been counselled, of whom 30 have completed the programme and received results. ${ }^{2}$ One serious error relating to blood sampling occurred, but not as a direct result of our own testing programme. It involved the family shown in the figure. Both parents were dead and no stored DNA samples were available Sibs II.5 and II.6, resident in NI, requested predictive testing. The other sibs (II.1-II.4), including two affected members, were resident elsewhere. DNA from the two affected members (II.1 and II.2) was sent to our molecular genetic laboratory. (These origina samples were taken in a regional hospita elsewhere by a consultant clinical geneticist, were sent to the regional DNA laboratory in a different hospital, and the extracted DNA then sent to another regional molecular genetics laboratory, as the original centre did not test for HD.) In Belfast, the samples were Southern blotted with probe YNZ32, ${ }^{3}$ with

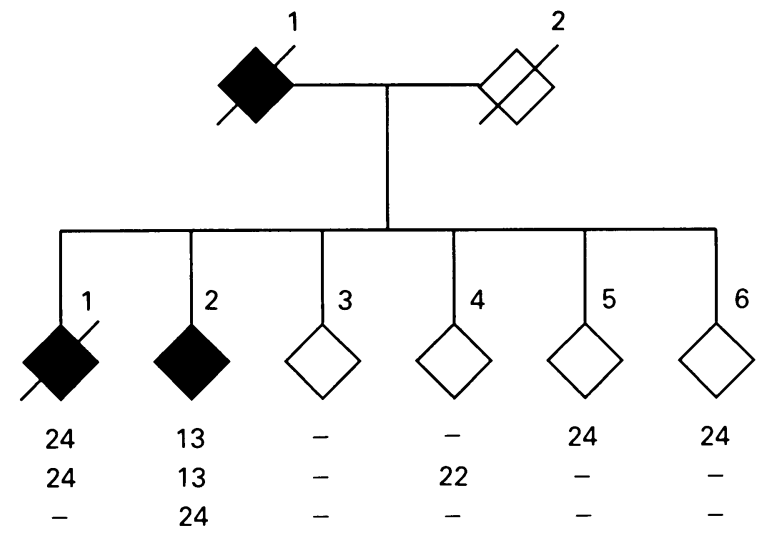

Sample 3

II

Sample 1

Sample 2

Pedigree of family undergoing testing, showing

samples run in adjacent lanes and with mixing of samples to allow clear resolution of all four alleles. This showed incompatible alleles in each of the two affected sibs, suggesting either non-paternity, recombination, or sample mix up. Non-paternity was confirmed using YNH24 probing, which showed five alleles in the family, with II. 2 having a fifth allele not present in the other sibs. Repeat samples were requested, and DNA from the original stock solutions was received, along with a DNA sample from sib II.4, who had recently requested predictive testing at that centre. We, in return, sent two DNA samples from our patients II.5 and II.6 to the regional centre elsewhere for concurrent testing.

Repeat testing of the two affected samples again showed incompatible allele types (figure). A request was made for the two patients to be re-bled. During this time patient II.1 had died and only a new DNA sample was received from II.2. This sample was different from the original II.2 sample and was consistent with the allele type in patient II.1 and with paternity testing. The revised results were immediately telephoned to the regional centre involved, who were already planning to disclose their results on sib II.4 which had appeared to be informative using another probe. Results in both centres were rechecked and the result on patient II.4, using a combination of YNZ32 and another probe, indicated an exclusion test result. Our own patients II.5 and II.6 remained uninformative on linkage based testing because of the lack of parental samples.

This problem clearly illustrates the importance of accurate sample taking, labelling, and storage. In this case the problem had probably arisen, not through initial faulty sample taking and labelling, but through sample labelling error either at DNA extraction or during labelling and transport of the samples between different genetic centres. Our own testing protocol, based on UK guidelines, ${ }^{45}$ was modified to include taking two samples on two separate occasions from each person entering the programme where the families were small. Sample results are now confirmed by analysis of the second sample before the disclosure session. This precaution reduces the risk of a similar problem occurring, and does not add greatly to the number of samples analysed. Since the introduction of the duplicate sampling in 1992, one pair of samples has since been identified as having been wrongly labelled after DNA extraction. With the use of multiallelic DNA probes, some cases of sample or paternity error have been identi- fied directly on allele mismatch. However, even with the use of multiallelic probes and paternity testing, errors may still not be detected, and computer simulated linkage analysis in HD found a $69 \%$ rate of inconsistency in some families. ${ }^{6}$ With the availability of direct testing for the IT 15 gene, ${ }^{7}$ samples can now be tested without using stored family DNA. Such a procedure still carries a risk of sample error, and new samples should be used when possible.

The application of DNA testing in late onset disorders such as neurological disease or cancer is likely to increase over the next 10 years. We strongly recommend the use of two separate DNA samples from key affected members in small families undergoing predictive testing for late onset genetic diseases, particularly where samples are transported from other medical or nursing staff. Strict adherence to DNA storage guidelines ${ }^{8}$ will further reduce avoidable error in $\mathrm{HD}$ and other predictive testing programmes.

PJM is supported by a Royal College of Physicians of Ireland Glaxo Fellowship in Molecular Biology.

\section{P J MORRISON A GRAHAM Department of Medical Genetic The Queen's University of Belfast, Floor $A$ Belfast City Hospital Tower, Lisburn Road Belfast $B T 97 A B, U K$}

1 Lazarou .LP, Meredith AL, Myring JM, et al. Huntington's disease: predictive testing and the molecular genetics laboratory. Clin Genet 1993; 43: 150-6.

2 Morrison PJ. The epidemiology and genetics of Huntington's disease. MD thesis, The Queen's Huntington's disease. MD the

3 Richards B, Horn GT, Merrill JJ, Klinger KW. Characterization and rapid analysis of the Characterization and rapid analysis of the
highly polymorphic VNTR locus D4S125 highly polymorphic VNTR locus D4S125 (YNZ32) closely related to the Huntingto
disease gene. Genomics 1991; 9: 235-40.

4 Tyler A, Ball D, Craufurd D, on behalf of the UK Huntington's Disease Prediction Consortium. Presymptomatic testing for Huntington's disease in the United Kingdom. $B M F$ 1992; 304: 1593-6.

5 Craufurd D, Tyler $A$, on behalf of the UK Huntington's Prediction Consortium. Predictive testing for Huntington's disease: protocol of the UK Huntington's prediction consortium. F Med Genet 1992; 29: 915-18.

6 King TM, Brandt J, Meyers DA. Effect of laboratory or clerical error on presymptomatic risk calculations for Huntington disease: a simulation study. Am $\mathfrak{7}$ Med Genet 1993; 46: 154-8.

7 tion study. Am f Med Genet 1993; 46: 154-8. Research Group. A novel gene containing a trinucleotide repeat that is expanded and unstable on Huntington's

8 Yates JRW, Malcolm S, Read AP. Guidelines for DNA banking. Report of the Clinical GenDNA banking. Report of the Clinical Genetics Society working party on
f Med Genet 1989; 26: $245-50$. 